\title{
Promoting the Use of Numerical Computing Tools among Students of Agricultural Engineering
}

\author{
Pau Martí, Elies Fuster-Garcia, Álvaro Royuela, and José Vicente Turégano
}

\begin{abstract}
This paper presents a didactic methodology for introducing students in the application of numerical computing tools for reference evapotranspiration estimation. Students learn a specific application of this software within their field of future professional competencies. Specifically, the session focuses on the application of these tools for assessing reference evapotranspiration according to two standard non-calibrated methods, as well as on proposing an improved version for the local climatic scenario. Through this specific practical application, students should become aware of the computing possibilities offered by this software in this specific subject in comparison to the time-consuming conventional procedures usually adopted. The lecturer should stress the generalizability of the training acquired by the students for solving specific real problems that they might find in other subjects, as well as in their professional future as agricultural engineers.
\end{abstract}

Index Terms-Agricultural engineering, computing tools, modeling.

\section{INTRODUCTION}

Mathematics is applied in a multitude of different ways in a huge variety of extra-mathematical subjects, fields and practice areas. Every time mathematics is used to deal with issues, problems, situations and contexts in domains outside of mathematics, mathematical models and modeling are necessarily involved, implicitly or explicitly. The utilization of mathematics in extra-mathematical contexts for extra-mathematical purposes is, in itself, an important activity and endeavor. Thus, it should be a primary goal and task of mathematics education to enable students at various levels to engage in such activities [1]. In Spain, most of the subjects scheduled in the syllabus corresponding to the Degree Programs of Agricultural Engineering require an important basis on mathematical fundamentals, like many other degrees of the engineering branch. Consequently, all engineering degrees include a general training on Mathematics during the first years, incorporating practical sessions in a computer lab with mathematical software like Matlab [2] or Octave [3] (one of the two major open-source alternatives to Matlab). Both software use a high-level technical computing language and include an interactive environment for algorithm development, data visualization, data analysis and numerical computing. They allow a huge variety of computational

Manuscript received August 3, 2015; revised October 12, 2015.

Pau Martíis, Álvaro Royuela, and José Vicente Turégano are with the Department of Rural and Agrifood Engineering, Universitat Politècnica de València, Spain (e-mail: paumarpe@hotmail.es, aroyuela@agf.upv.es, jturegan@agf.upv.es).

Elies Fuster-Garcia is with ITACA Institute, Universitat Politècnica de València, València, Spain (e-mail: elfusgar@itaca.upv.es). possibilities and have become a very valued tool for all kind of engineers. Nevertheless, in contrast to other degrees, among others Mechanical and Electrical Industrial Engineering or Civil Engineering, this general numerical computing training is not extended in further subjects of the degree program of Agricultural Engineering with a focus on specific real problems that students might find in their professional future as engineers. Due to this lack of specific training, the use of excel or similar tools is very extended within agricultural engineers for managing matrices and performing mathematical operations.

This processes can be often tedious and time-consuming, especially if large matrices are considered of routine-based calculations must be manually carried out, which could additionally derive in errors. This omission of practical mathematical training becomes especially noteworthy or even dramatic for students who begin a scientific career after getting the Bachelor diploma and realize the importance of having a sound mathematical training for performing modeling tasks, among others. This fact can be proven attending to the scientific studies published by Spanish researchers in the branch of agricultural sciences, especially focusing on researchers with a degree in Agricultural Engineering. The computing possibilities offered, among others, by Matlab or Octave, are acknowledged by most agricultural researchers, who, at the same time, feel, a priori, not able to use it for their research purposes.

In our opinion this pattern might be partially offset with the introduction of further training activities in the subjects of the Degree syllabus. New activities tackling the development of models, including practical sessions with the help of mathematical software, would be of high interest and benefit for the students of Agricultural Engineering. This would contribute not only to acquire knowledge about modeling approaches and the use of mathematical software, but also to a better and deeper understanding of the studied physical processes. Moreover, dealing with the activation of mathematics in extra-mathematical contexts for extra-mathematical purposes can foster motivation with students for the study of mathematics and help support and consolidate their concept formation, sense-making and experience of meaning in and of mathematics [1].

This paper presents a pedagogical proposal for the subject 'Irrigation Engineering' corresponding to the Degree of Agricultural Engineering at the Universitat Politècnica de València (Technical University of Valencia). The presented proposal aims at introducing and promoting the use of Matlaband Octave within students through the development of specific applications encountered in the professional practice linked to this subject. It is important to point out that 
the activity intends not only to present a specific modeling application contextualized in an attractive professional scenario for the student. It is very important that the lecturer stresses the generalizability and usefulness of the computational procedures for other applications encountered in this subject and in other subjects of the degree program. Specifically, the presented application example deals with the modeling and estimation of crop water requirements.

The design and management of irrigation installations are included among the most important competences of Agricultural Engineers. Therefore several subjects of this area are scheduled in the syllabus corresponding to the Degree of Agricultural Engineering, among others, 'Hydraulic Engineering' and 'Irrigation Engineering'. Water use in irrigated agriculture is a paramount issue for different aspects of water resources management, such as planning and design of new irrigation districts and systems and water distribution among existing districts. Accurate knowledge of crop water requirements is required to deal with these issues, and the key parameter to quantify these water requirements is called evapotranspiration (ET). Irrigation needs are calculated according to the amount of water used by crop ET. Reference evapotranspiration (ETo) is defined as the potential ET of a hypothetical surface of green grass of uniform height, actively growing and suitably watered, and was introduced to express the evaporative demand of the atmosphere independent of management practices, crop type and development.

Evapotranspiration can be directly measured by high-cost techniques. Further, it is rather difficult or costly to be measured. Thus, different mathematical models have been proposed as an alternative. Although the Food and Agriculture Organization (FAO) version of the Penman Monteith equation [4], FAO56-PM, has shown in general accurate and sound performance for estimating ETo in different climatic scenarios, and was therefore recommended as the sole standard method for calculating ETo and validating other equations, its application is not possible in many situations, because it requires a lot of climatic inputs which might be not available or reliable. Therefore, estimating ETo with empirical methods is commonly required at local scale for water resources and irrigation management and planning.

The study and development of temperature-based methods is justified for several reasons. First, temperature and solar radiation explain at least $80 \%$ of ETo. Second, temperature is the most diffusely monitored variable among the ones needed for ETo estimation. The well-known Hargreaves (HG) equation [5], [6] requires only measured mean air temperature and temperature range, as well as calculated extraterrestrial radiation. Although accurate daily estimates have been reported, the best $\mathrm{HG}$ estimates might be expected for five-day or longer periods. Nevertheless, numerous agricultural and hydrological applications require daily ETo data. Several researchers have found out over- and underestimation patterns of the HG equation in humid and dry scenarios, or if advection is involved. So, HG estimates should not be overextended to different climatic conditions unless it has been previously locally calibrated. This calibration might be performed using ETo measurements or, more commonly, Penman Monteith calculated benchmarks, considering in most cases a regression-based regionally calibrated empirical Hargreaves coefficient. However, these equations are site-specific and cannot be extrapolated to other locations where local ETo benchmarks are not available. Indeed, in stations where a local calibration is possible, the FAO56-PM equation would be used in practice, leaving the calibrated HG equation for emergency cases. Accordingly, in addition to local linear calibration, different authors have tackled the parametric calibration of the HG coefficient relying on additional parameters, such us temperature range (Samani, [7]) or the ratio mean temperature/temperature range (Vanderlinden et al. [8]).

ETo can be considered as a climatic parameter and its calculation relies on other climatic inputs, i.e. its modeling and assessment requires to handle climatic data series, which are usually very large. Currently these operations are usually very time-consuming, because students (and lecturers) usually carry out them with excel. The presented proposal aims at assessing ETo in 16 local stations based on the mentioned standards FAO56-PM and HG, as well as developing new parametric calibrations of the adjusted Hargreaves coefficient (AHC) relying on temperature range and on ratio mean temperature/temperature range. Further, the calculations will consider two different time steps, i.e. daily and monthly ETo estimates.

\section{MethodOlOGY}

Before beginning with the specific application of Matlab for handling the climatic data series, the most important Matlab commands required for the proposed problem will be briefly remembered. This session aims at taking advantage of the general Matlab training acquired by the students in the first year of the degree schedule. The lecturer will provide previously a file containing the climatic data series for the calculations. It is important to notice that although the code was originally written on Matlab, it can be easy adapted to Octave (the main open-source alternative to Matlab), due to they use a language that is mostly compatible.

\section{A. Data Set and Study Area}

The data used for this study are daily values of maximum $\left(T_{\text {max }}\right)$, minimum $\left(T_{\min }\right)$ and mean $\left(T_{\text {mean }}\right)$ air temperature, relative humidity $(\mathrm{RH})$, solar radiation $\left(R_{s}\right)$, and wind speed $\left(\mathrm{u}_{2}\right)$ comprising the period 2000-2007 in 16 (8 coastal and 8 inland) weather stations located in the Mediaterranean coast of Spain, Fig. 1. Data were provided by the Service of Irrigation Technology from the Valencian Institute of Agricultural Research.

First, data will be imported and stored as Matlab computing elements in form of cells. These cells contain the data series for the study, being arranged as days in rows and climatic variables in columns. Second, a short program will be implemented to exclude outliers. This program should scan all matrices excluding measurements lying beyond the defined allowable confidence interval (for instance mean \pm 2 times the standard deviation). The corresponding rows should be excluded from the data series. Afterwards, a second m-file will be implemented by the students to calculate mean monthly averages for all variables and stations. They should 
take advantage of the first four columns included in the matrices, namely day of the year, day of the month, month of the year and year. When these average values are computed, the standard conventional $E T_{o}$ estimates mentioned in the introduction are calculated in a further m-file. These methods are described in the next subsections.

TABLE I: GEOGRAPHICAL CHARACTERIZATION OF THE STUDIED LOCATIONS

\begin{tabular}{|c|c|c|c|c|c|}
\hline Station & $\overline{c^{a}}$ & $\varphi$ & $\tau^{b}$ & $z$ & $\bar{d}$ \\
\hline $\begin{array}{l}\text { Pilar de la } \\
\text { Horadada }\end{array}$ & $\mathrm{C} 1$ & 37.8700 & 0.8103 & 77 & 4.7 \\
\hline Altea & $\mathrm{C} 2$ & 38.6056 & 0.0775 & 210 & 2.5 \\
\hline Vila Joiosa & $\mathrm{C} 3$ & 38.5294 & 0.2553 & 138 & 3.4 \\
\hline $\begin{array}{l}\text { Tavernes } \\
\text { Valldigna }\end{array}$ & $\mathrm{C} 4$ & 39.0964 & 0.2367 & 15 & 1.6 \\
\hline Sagunt & $\mathrm{C} 5$ & 39.6492 & 0.2925 & 33 & 4.4 \\
\hline Benavites & C6 & 39.7333 & 0.2150 & 8 & 2.7 \\
\hline Ondara & $\mathrm{C} 7$ & 38.8197 & $\begin{array}{l}-0.007 \\
5\end{array}$ & 49 & 1.1 \\
\hline Dénia & $\mathrm{C} 8$ & 38.7939 & $\begin{array}{l}-0.083 \\
6\end{array}$ & 102 & 11.1 \\
\hline Castalla & I1 & 38.6053 & 0.6728 & 708 & 31.8 \\
\hline Orihuela & $\mathrm{I} 2$ & 38.1828 & 0.9536 & 99 & 28.4 \\
\hline Turís & I3 & 39.4006 & 0.6836 & 299 & 30.2 \\
\hline Pedralba & I4 & 39.5678 & 0.7164 & 200 & 34.8 \\
\hline Llíria & I5 & 39.6919 & 0.6253 & 250 & 33.2 \\
\hline Cheste & I6 & 39.5217 & 0.7417 & 323 & 36.2 \\
\hline El Pinós & I7 & 38.4286 & 1.0594 & 606 & 49.5 \\
\hline $\begin{array}{l}\text { Camp de } \\
\text { Mirra }\end{array}$ & I8 & 38.6803 & 0.7717 & 627 & 43.6 \\
\hline
\end{tabular}

$\varphi$ : latitude $\left({ }^{\circ}\right) ; \tau$ : longitude $\left(^{\circ}\right) ; z$ : altitude $(\mathrm{m}) ; d$ : minimum distance to the sea $(\mathrm{km})$. Station code (C coastal, I inland); Positive values: West longitude; negative values: East, with respect to the Greenwich meridian.

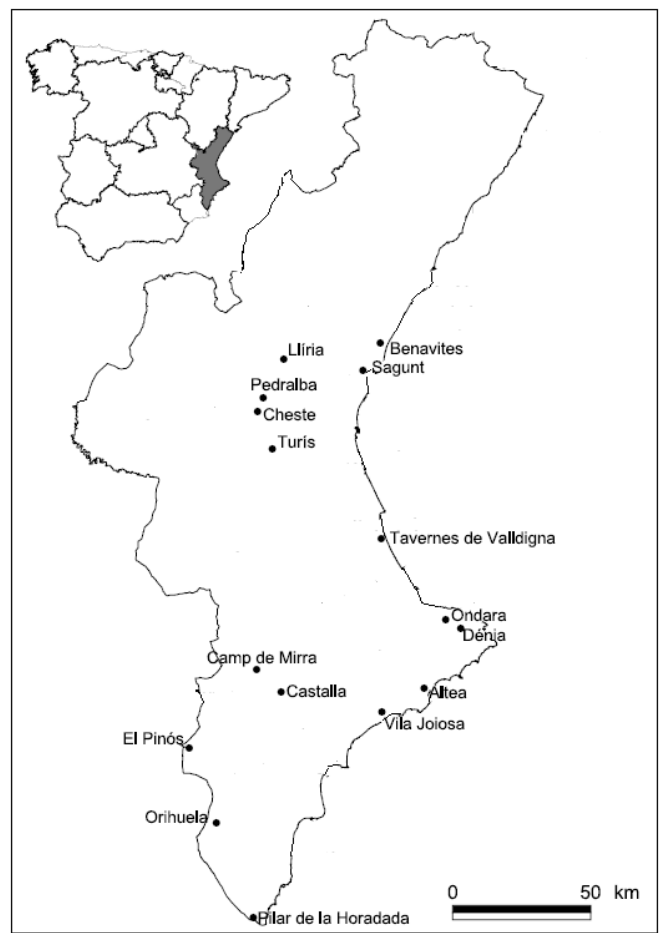

Fig. 1. Location of studied stations.

\section{B. Approaches to Estimate $E T_{o}$}

FAO56 Penman Monteith equation: Experimental ETo measurements are complex and expensive. Therefore, according to the FAO, the PM equation was is to provide the targets to calibrate and test the empirical equations [4]. Thus, for daily estimates

$$
E T_{o}^{P M}=\frac{0.408 \Delta\left(R_{n}-G\right)+\gamma \frac{900}{T+273} u_{2}\left(e_{s}-e_{a}\right)}{\Delta+\gamma\left(1+0.34 u_{2}\right)}
$$

where $E T_{o}^{P M}$ is the reference evapotranspiration calculated with the FAO-56 Penman-Monteith method ( $\mathrm{mm} /$ day); $R_{n}$ is the net radiation at the crop surface $\left(\mathrm{MJ} / \mathrm{m}^{2} /\right.$ day); $G$ is the soil heat flux density $\left(\mathrm{MJ} / \mathrm{m}^{2} /\right.$ day); $T$ is the mean daily air temperature at $2 \mathrm{~m}$ height $\left({ }^{\circ} \mathrm{C}\right) ; \gamma$ is the psychrometric constant $\left(\mathrm{kPa} /{ }^{\circ} \mathrm{C}\right) ; \Delta$ is the slope vapor pressure curve $\left(\mathrm{kPa} /{ }^{\circ} \mathrm{C}\right) ; e_{s}$ is the saturation vapor pressure $(\mathrm{kPa}) ; e_{a}$ is the actual vapor pressure $(\mathrm{kPa}) ; u_{2}$ is the wind speed at $2 \mathrm{~m}$ height $(\mathrm{m} / \mathrm{s})$. All parameters were calculated applying the equations provided by Allen et al. [4]. G was assumed to be zero throughout the daily calculation time step periods according to Allen et al. [4]. For the monthly time step, G was calculated as

$$
G_{\text {month } i}=0.07\left(T_{\text {month } i+1}-T_{\text {month } i-1}\right)
$$

where $G_{\text {monthi }}$ is the soil heat flux in the month $i, T_{\text {month } i+1}$ is the average mean temperature in the month $i+1$, while $T_{\text {month } i-1}$ is the average mean temperature in the month $i-1$.

Hargreaves equation: The classical expression of the HG equation [5] for daily estimates is:

$$
E T_{o}^{H}=C_{1} R_{a}(T+17.8) \sqrt{\Delta T}
$$

where $E T_{o}{ }^{H}$ is the reference evapotranspiration calculated by the Hargreaves method ( $\mathrm{mm} /$ day); $R_{a}$ is the water equivalent of extraterrestrial radiation ( $\mathrm{mm} /$ day); $\Delta T$ is the daily temperature range $\left({ }^{\circ} \mathrm{C}\right) ; T$ is the mean daily air temperature $\left({ }^{\circ} \mathrm{C}\right), C_{1}$ is the Hargreaves empirical coefficient, equal to 0.0023. The equation was developed from two equations, namely:

$$
E T_{o}^{H}=0.0135 R_{S}(T+17.8)
$$

and

$$
R_{S}=C_{2} R_{a} \sqrt{\Delta T}
$$

where $R_{s}$ is the solar radiation, and $C_{2}$ is an empirical coefficient.

For the development of the m-files, the lecturer should stress that the variables have to be handled as vectors, and therefore, both equations must be adapted. This program should compute automatically all daily and monthly estimations for all years and stations considered. Therefore, students should learn to apply routine-based procedures to reduce the time invested.

\section{Calibration of the Hargreaves Equation}

There are two common procedures to calibrate the $\mathrm{HG}$ equation, either a direct calibration using experimental or calculated FAO56-PM $E T_{o}$ targets or the application of parametric equations for the adjustment coefficients relying on further variables. Taking advantage of the FAO56-PM 
targets, the calibrations is usually carried out according to a simple linear regression

$$
E T_{o}^{P M}=a \cdot E T_{o}^{H G}
$$

Samani [7] proposed a new formulation based on the analysis of the annual average of monthly temperature range and radiation for a period of 25 years across 65 stations in the US. Namely,

$$
C_{2}=0.00185 \Delta T^{2}-0.0433 \Delta T+0.4023
$$

Vanderlinden et al. [8] proposed a new expression for C1 based on the analysis of 16 weather stations in Southern Spain for a period of 38 years, with the structure

$$
C_{1}=0.0005 \frac{T}{\Delta T}+0.00159
$$

where $T$ and $\Delta T$ correspond to average mean temperature and temperature range per station.

According to these equations, students will perform three calibrations types. First, they will apply linear regression to obtain the actual a value per station. The adjusted Hargreaves coefficient (AHC) will be obtained as a*0.0023. Second, a linear parametric calibration according to Vanderlinden $e t$ al. [8] will be obtained. Finally, a quadratic parametric calibration according to Samani [7] will be obtained. For cases 2 and 3, a preliminary calculation of average $T_{\text {mean }}$ and temperature range per station is required. The actual AHC values previously obtained will be used for the parametric calibrations, too. The new equations will be used to calculate the calibrated HG estimates per station, which will be assessed using the parameters presented in the next subsection. The individual AHC values calculated per station will be compared using barplots. Finally, a further case will be studied, the assessment of daily accumulated average $\mathrm{ET}_{\mathrm{o}}$ estimates. Therefore, students will have to calculate a mean daily value for the 8 years. Afterwards a daily accumulated estimate value will be calculated for the HG estimates considered.

\section{Performance Evaluation}

The student will assess the model accuracy through the calculation of several error parameters. The average absolute relative error $(A A R E)$, and the mean absolute error $(M A E)$ will be obtained according to equations 9 and 10, respectively, being $\mathrm{x}_{\mathrm{i}}$ the actual value of $E T_{o}$ and $\hat{x}_{i}$ the prediction. $\mathrm{n}$ was the total number of data in the $E T_{o}$ matrix. The $A A R E$ is unitless. The units of the MAE are mm/day.

$$
\begin{aligned}
& \text { AARE }=\cdot \frac{1}{n} \sum_{i=1}^{n} \frac{\left|x_{i}-\hat{x}_{i}\right|}{\hat{x}_{i}} \\
& M A E=\frac{1}{n} \cdot \sum_{i=1}^{n}\left|x_{i}-\hat{x}_{i}\right|
\end{aligned}
$$

Finally, the coefficient of determination $R^{2}$ was calculated as follows, where $\sigma_{x_{i}}$ and $\sigma_{\hat{x}_{i}}$ are the standard deviations of observed and predicted $E T_{o}$ values, respectively.

$$
R^{2}=\left(\frac{\operatorname{cov}\left(x_{i}, \hat{x}_{i}\right)}{\sigma_{x_{i}} \cdot \sigma_{\hat{x}_{i}}}\right)^{2}
$$

being $x_{i}$ the actual value of $E T_{o}$ and $\hat{x}_{i}$ the estimation.

\section{RESULTS}

After the corresponding explanations of the lecturer, the students will present the results of their calculations using different plots, which will be discussed.

\section{A. Comparison of Adjusted Hargreaves Coefficients (AHC)}

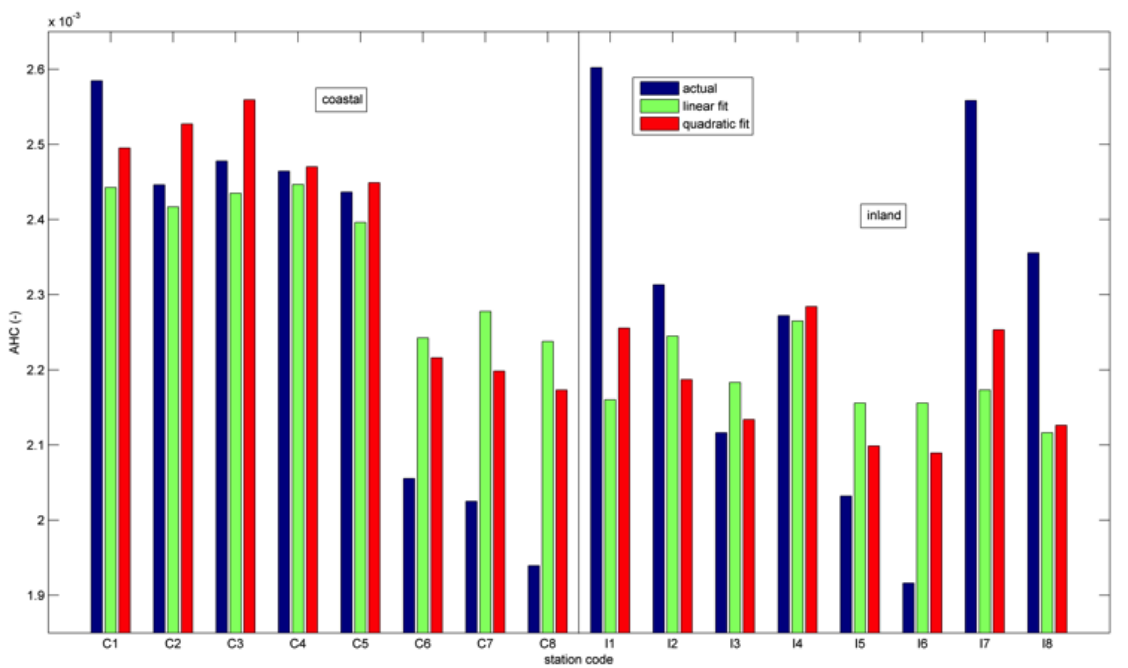

Fig. 2. Comparison of AHC values per station.

First, a comparison will be carried out between the different approaches used to calculate the AHCs. Therefore a barplot representing the AHC values per station will be provided (Fig. 2). Students might assess the AHC values obtained in relationship with the coastal or inland character of the stations. Normally, the Hargreaves equation tends to underestimate $E T_{o}$ in coastal areas, where $\Delta T$ decreases due to the influence of the sea. This is enhanced by high wind velocity, which 
tends to reduce $\Delta T$ even more, by mixing the lower layers of the atmosphere. On the other hand, the Hargreaves equation tends to overestimate $E T_{o}$ in inland mountainous areas, where air mass movement raises $\Delta T$. Therefore, they might find out reasons for explaining AHC values over 0.0023 in coastal stations and values under 0.0023 in inland stations.

\section{B. Global Error Measures per Station}

The next task intends to compare the error measures of the different calibration approaches per station considering daily and monthly time steps (Fig. 3 and Fig. 4).
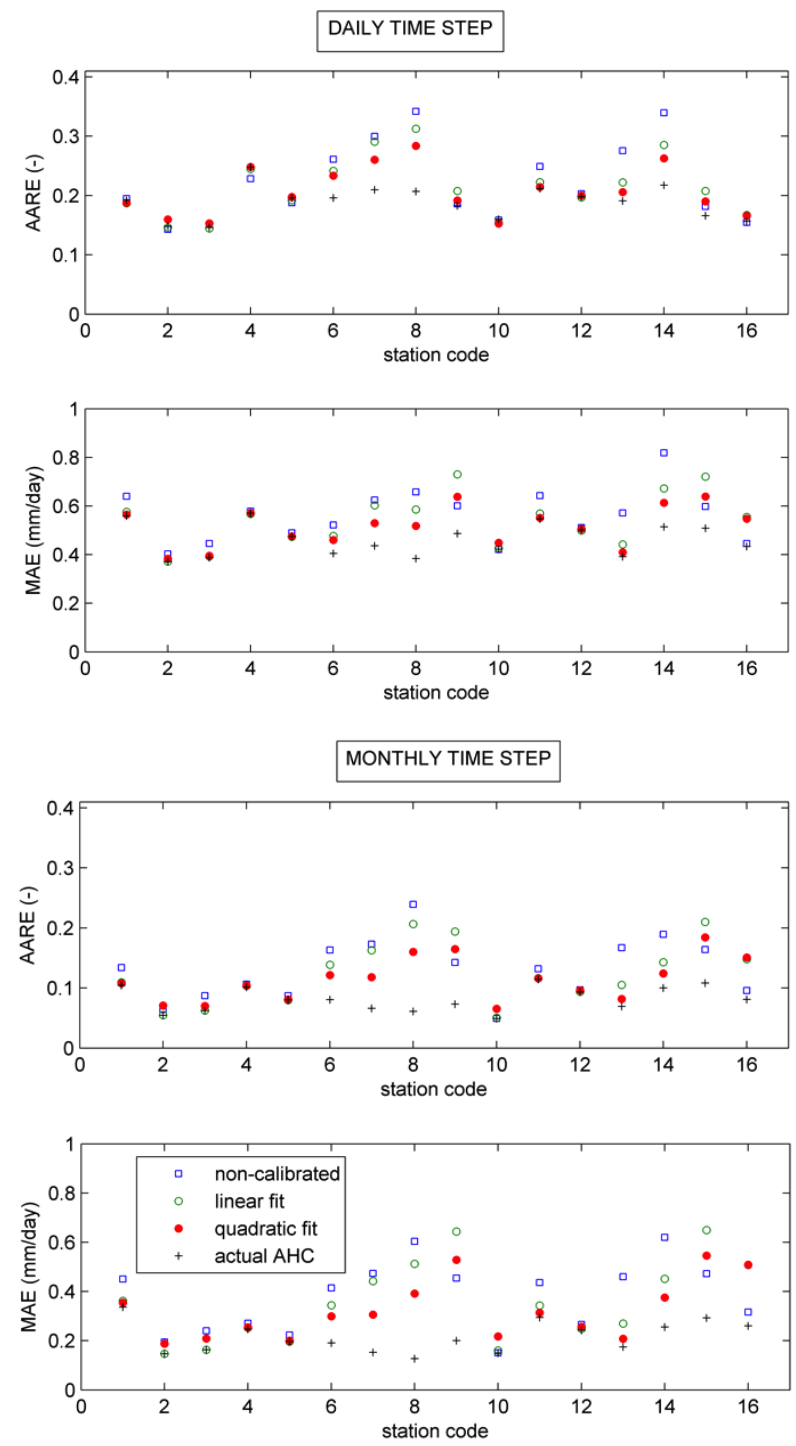

Fig. 3. $A A R E$ and $M A E$ values per station and time step considered.

After calibration, the error measures tend to decrease considerably. The general trend of estimation in coastal and inland stations, respectively, are very site-specific and depend on the specific climatic patterns used for calibrating.

\section{Accumulated Estimates per Station}

Again, a $2 \times 2$ subplot will be provided to compare the accumulated ETo trends in two representative stations (one coastal and one inland stations) presenting under- or overestimation patterns, respectively. The students should previously analyze the estimates, computing eventually a further index (the mean bias error) for detecting those under-/overestimation trends. Afterwards, they would proceed with the calculation of the average accumulated values and their graphical representation (Fig. 4).
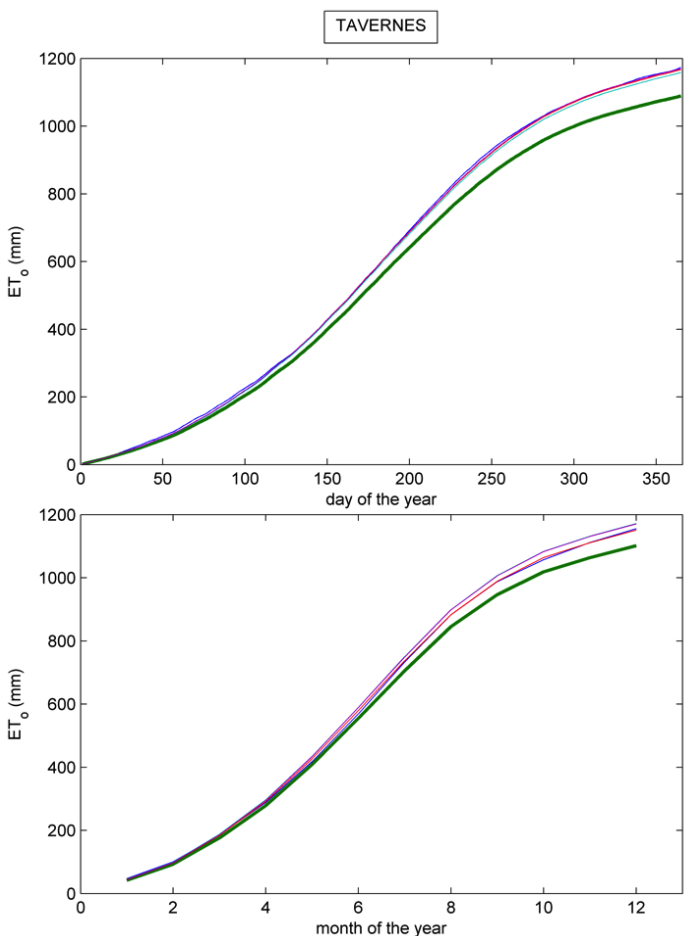

LLIRIA
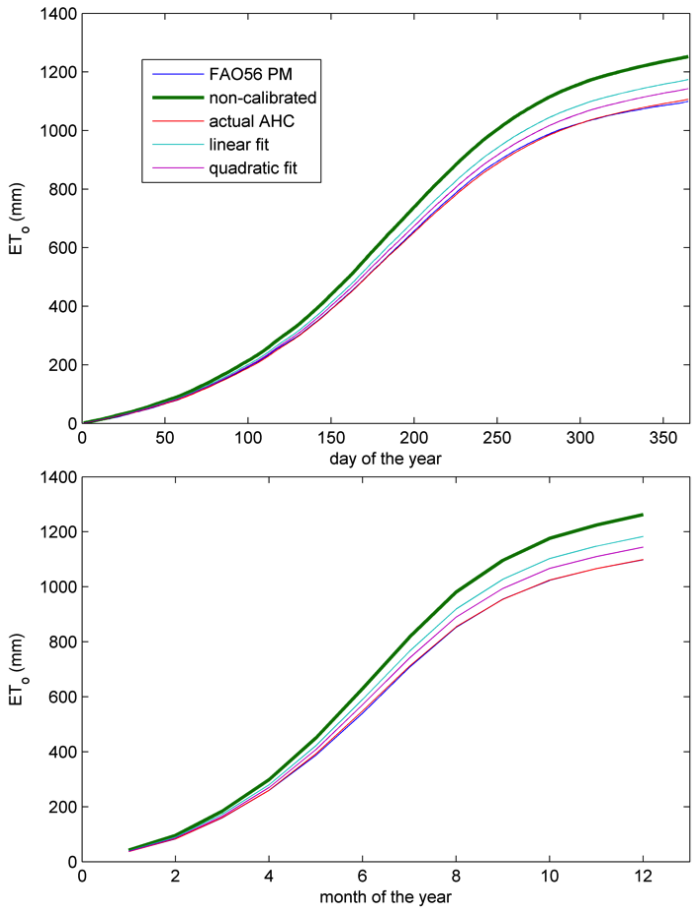

Fig. 4. Accumulated $E T_{o}$ estimates in Tavernes and Lliria.

\section{New Parametric Expressions for the AHC}

The new expressions for calculating $A H C$ in the Valencia region would be

1) Linear fit (according to Vanderlinden et al. [8])

$$
A H C_{V}=0.0003 \frac{T}{\Delta T}+0.00178
$$

2) Quadratic fit (according to Samani [7])

$$
A H C_{S}=0.00072 \Delta T^{2}-0.024 \Delta T+0.341
$$


This study case allows considering a further application for visualizing the soundness and modeling potential offered by this software, namely modeling $E T_{o}$ with artificial neural networks (ANN). In this case, new ANN models relying on the same input combinations considered here would be trained and tested, eventually through different validation scenarios (hold out, k-fold, leave one out...) This study would take advantage of the Matlab Neural Network Toolbox, which would enable an easy ANN application by the students, without having to implement a specific $\mathrm{m}$-file, which would be more complex for them.

\section{DISCUSSION AND CONCLUSIONS}

Students of Agricultural Engineering in Spain don't enhance their general numerical computing training, acquired usually during the first year of the degree program, through further applications of the software for solving problems in more applied subjects, linked to their professional future tasks as engineers. This lack of numerical computing training for facing real problem applications might be realized late when real problems demand rapid responses during normal engineering practice, already as agricultural engineers. This lack of training might be even more noteworthy for graduates beginning a scientific career, where a sound modeling training might be decisive. The introduction of further applications with Matlab or Octave between other alternatives for solving Agricultural Engineering problems should be desirable for compensating this lack of training. Therefore, new practical sessions in the computer lab would be of great interesting in other subjects of the degree program.

This paper presents a new practical session for the subject 'Irrigation and Drainage', corresponding to the Degree of Agricultural Engineering at the Universitat Politècnica de València. The presented application aims at introducing to the students a new and robust mathematical tool for a specific and important application of the subject, the calculation of crop water requirements. Specifically, students use Matlab for assessing the estimation of reference evapotranspiration, a key a parameter in irrigation, through well-known models in this area, as well as for developing two new parametric calibrations of a very used temperature-based approach, both considering daily and monthly time steps. A second practical session in this subject might tackle the application of artificial neural networks for modeling reference evapotranspiration based on the same model inputs considered here. Therefore, students could take advantage of the neural network toolbox, and other friendly environments offered by Matlab for non-specialized staff.

The students should become aware of the great computational possibilities offered by the numerical computing software when facing a real specific problem that might be encountered in this subject, and in other subjects. They should also realize that the theoretical training acquired in other subjects could be easily translated into a real ability to solve a huge variety of problems in agricultural engineering, where commonly simpler and time-consuming tools are used.

\section{ACKNOWLEDGMENT}

The authors are grateful to the Institut Valenciàd'Investigacions Agràries (IVIA) for providing the meteorological data set used in the present work.

\section{REFERENCES}

[1] M. Niss, Models and Modelling in Mathematics Education, EMS Newsletter, pp. 49-51, 2012.

[2] Matlab, User's Manual Version 7.4.0 (R2007a), The Math Work Inc., Natick, Mass, 2007.

[3] J. W. Eaton, D. Bateman, and S. Hauberg, GNU Octave Manual, Network Theory Ltd., 2008.

[4] R. G. Allen, L. S. Pereira, D. Raes, and M. Smith, "Crop evapotranspiration," Guidelines for Computing Water Requirements, FAO, Rome, 1998

[5] G. H. Hargreaves and Z. A. Samani, "Reference crop evapotranspiration from ambient air temperature," Appl. Eng. Agric., vol. 1, no. 2, pp. 96-99, 1985.

[6] G. H. Hargreaves and R. G. Allen, "Historyandevaluation of Hargreaves evapotranspiration equation," J. Irrig. Drain. Eng., vol. 129, no. 1, pp. 53-63, 2003.

[7] Z. Samani, "Estimating solar radiation and evapotranspiration using minimum climatological data," J. Irrig. Drain. Eng., vol. 126, no. 4, pp. 265-267, 2000.

[8] K. Vanderlinden, J. V. Giráldez, and M. Meirvenne, "Assessing reference evapotranspiration by the hargreaces method in Southern Spain,” J. Irrig. Drain. Eng., vol. 130, no. 3, pp. 184-191, 2004.

Pau Martí received his B.S., M.A. and Ph.D. degrees in agricultural engineering from the Universitat Politècnica de València, Spain. He is currently an assistant professor at the Department of Biology of the Universitat de les Illes Balears. His main research interests focus on irrigation engineering, hydrology and agrometeorology.

Elies Fuster-Garcia received his Ph.D. degrees in applied physics from the Universitat Politècnica de València, Spain. He is currently a postdoctoral researcher at ITACA Institute of the Universitat Politècnica de València. His main research interests focus on machine learning, modeling, and signal and image automatic analysis.

Álvaro Royuela received his B.S., M.A. and Ph.D. degrees in agricultural engineering from the Universitat Politècnica de València, Spain. He is currently an associate professor at the Department of Rural and Agrifood Engineering of the Universitat Politècnica de València. His main research interests include estimation of irrigation needs, efficiency of irrigation and design of pressured irrigation subunit.

José Vicente Turégano Pastor received his B.S., M.A. and Ph.D. degrees in agricultural engineering from the Universitat Politècnica de València, Spain. He is currently an associate professor at the Department of Rural and Agrifood Engineering of the Universitat Politècnica de València. His main research interest include efficiency of irrigation and design of pressured irrigation subunit 